\title{
Estimation of Pramipexole Dihydrochloride in Tablet Formulation by the Developed Reverse Phase High Performance Liquid Chromatography Method and its Validation
}

\author{
P. VENKATESH AND S. GAYATRI*
}

Faculty of Pharmacy, Sri Ramachandra Institute of Higher Education and Research, Chennai, Tamil Nadu 600116, India

Venkatesh et al.: Estimation of Pramipexole by Reverse Phase High Performance Liquid Chromatography

A simple, rapid isocratic reverse phase high performance liquid chromatography method was developed and validated for the determination of pramipexole dihydrochloride in tablet dosage form as per International Council on Harmonisation guidelines. In this method the chromatographic separation was carried out using C18 column with ultraviolet detector set at $264 \mathrm{~nm}$. The eluent consisted of acetonitrile:phosphate buffer (pH 4.0) (70:30 by volume) with a flow rate of $1 \mathrm{ml} / \mathrm{min}$. The method showed linear response with the retention time of $\mathbf{2 . 2 8} \mathrm{min}$. The main advantage of the developed method is its cost effectiveness and shortened run time. Hence this method can be applied for routine analysis of pramipexole in pharmaceutical dosage form.

Key words: Pramipexole, high performance liquid chromatography, method development, validation

Pramipexole [(S)-N6-propyl-4,5,6,7-tetrahydro-1,3benzothiazole-2,6-diamine] is used alone or with other medications as antidyskinetic agent to treat the symptoms of Parkinson's disease and also used to treat Restless Legs Syndrome (RLS). Pramipexole is a non-ergoline agonist with selectivity for D3 dopamine receptors. It works by acting as substitution for dopamine that is needed to control movement. Pramipexole has shown successful results in eliminating clinical symptoms of RLS. It is also being investigated for the treatment of clinical depression and fibromyalgia ${ }^{[1]}$.

Various analytical methods have been reported in the literature for the determination of pramipexole dihydrochloride in its pure form and in combination with other drugs. Methods using Ultraviolet (UV) spectrophotometer, Ultra-Performance Liquid Chromatography (UPLC), High Performance Liquid Chromatography-Mass Spectrometry (HPLC-MS), Gas Chromatography-Mass Spectrometry (GC-MS) have been employed for the analysis of pramipexole ${ }^{[2-9]}$.

The aim of this study is to develop a simple, efficient and validated HPLC method, using UV detection to quantify pramipexole dihydrochloride in the tablet dosage form.

*Address for correspondence

E-mail: gayatrisru@yahoo.co.in

January-February 2022
The HPLC analysis was performed on Shimadzu LC2010HT, equipped with C18 $(250 \times 4.6 \mathrm{~mm}, 5 \mu \mathrm{m})$ column, attached with an UV detector.

Chemicals and reagents used in this study were shown below. Ultra-pure water filtered through a $0.45 \mu \mathrm{m}$ Millipore Polyvinylidene Difluoride (PVDF) filter and Acetonitrile (HPLC grade) from Avantor chemicals Pvt. Ltd were used in the study. Pramipexole dihydrochloride reference standard was gifted by Alembic Pharmaceuticals Limited, Gujarat, India. Structure of pramipexole dihydrochloride is shown in fig. 1.

Phosphate buffer was prepared by dissolving $5.04 \mathrm{~g}$ of disodium hydrogen phosphate and $3.01 \mathrm{~g}$ of potassium dihydrogen phosphate in water to produce $1000 \mathrm{ml}$. The $\mathrm{pH}$ of the solution was adjusted to 4.0 using glacial acetic acid.

This is an open access article distributed under the terms of the Creative Commons Attribution-NonCommercial-ShareAlike 3.0 License, which allows others to remix, tweak, and build upon the work non-commercially, as long as the author is credited and the new creations are licensed under the identical terms

Accepted 22 February 2022 Revised 24 August 2021 Received 01 March 2020 Indian J Pharm Sci 2022;84(1):228-231 
The mobile phase was prepared by mixing phosphate buffer and acetonitrile in the ratio of 3:7. The homogenous mixture was filtered through $0.45 \mu \mathrm{m}$ membrane filter using vacuum filter. Then the solution was degassed using ultra sonicator for $20 \mathrm{~min}$. The prepared mobile phase is also used as diluent for the sample and standard.

Standard stock was prepared by dissolving $10 \mathrm{mg}$ of the accurately weighed pramipexole reference standard powder using the mobile phase solution then it is diluted to the concentration of $5,10,15,20,25$ and $30 \mu \mathrm{g} / \mathrm{ml}$.

Pramipexole $1 \mathrm{mg}$ tablet was collected from the local pharmacy. 20 tablets were weighed and powdered finely. A weight equivalent to $2 \mathrm{mg}$ was taken and transferred to a $10 \mathrm{ml}$ volumetric flask, dissolved by sonication and the volume was adjusted using mobile phase.

Chromatographic conditions used in the study were shown here. The analysis of pramipexole was carried out on Shimadzu LC-2010HT, equipped with C18 $(250 \times 4.6 \mathrm{~mm}, 5 \mu \mathrm{m})$ column with a flow rate of 1 $\mathrm{ml} / \mathrm{min}$ and the injection volume of $20 \mu \mathrm{l}$ in ambient temperature. The concentrations of the buffer and acetonitrile were optimized to give symmetric peak with short run time. The detection wavelength was set to $262 \mathrm{~nm}$ as determined by Shimadzu UV 1800 spectrophotometer.

Accurately weighed pramipexole (reference standard) equivalent to $10 \mathrm{mg}$ was diluted with $3: 7$ ratio of phosphate buffer and acetonitrile and scanned between $200 \mathrm{~nm}$ and $400 \mathrm{~nm}$ by UV spectroscopy.

Optimization of the chromatographic conditions was described below. To develop simple and efficient Reverse Phase High Performance Liquid Chromatography (RPHPLC) method for the analysis of pramipexole in tablet dosage, the optimum chromatographic conditions were selected based on the various literature review and trial and error. First the mobile phase of ammonium acetate buffer and acetonitrile was tried but good peak symmetry was obtained when using phosphate buffer ( $\mathrm{pH}$ adjusted using glacial acetic acid).

The following mobile phase concentrations were tried phosphate buffer:acetonitrile (70:30); phosphate buffer:acetonitrile (50:50); phosphate buffer:acetonitrile (30:70). The best peak with minimum retention time was achieved using the mobile phase ratio phosphate buffer:acetonitrile (30:70).

The optimum wavelength for detection of pramipexole was determined using UV-visible spectrophotometer and the maximum absorbance was achieved at $262 \mathrm{~nm}$. The spectrum was shown in the fig. 2 .

System suitability parameters like column efficiency, theoretical plate count and tailing factor were recorded ${ }^{[10-12]}$. The column efficiency should be more than 2000 United States Pharmacopoeia (USP) plate count, USP tailing for the peak should not be more than 1.5 and percentage Relative Standard Deviation (\% RSD) of the standard solution should not be more than $2.0 \%$. The result is shown in Table 1 . The chromatogram of pramipexole standard and sample were presented in fig. 3 .

Standard stock solutions containing pramipexole with concentration of $5 \mu \mathrm{g} / \mathrm{ml}$ to $30 \mu \mathrm{g} / \mathrm{ml}$ were prepared, in triplicate. Linearity was determined using linear regression equation. Calibration curve was plotted between concentration and peak area. Linearity and regression characteristics were found to be $y=23182 x+3673$ and 0.999 respectively and the results are discoursed in Table 1.

Limit of Detection (LOD) and Limit of Quantification (LOQ) was calculated. LOD is the point at which the analysis is feasible and considered as the lowest concentration in a sample that can be identified. LOQ is the lowest concentration of analyte at which quantitative results can be estimated with a high degree of accuracy and precision.

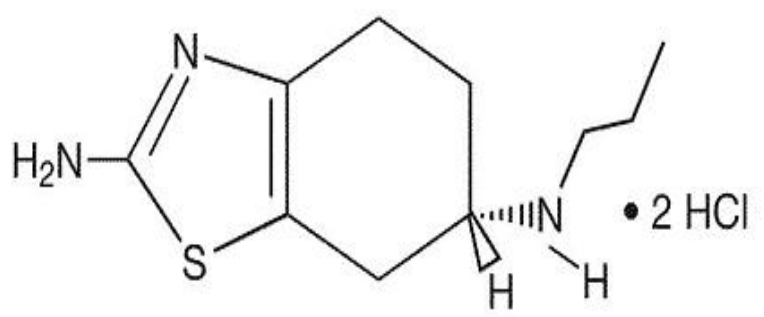

Fig. 1: Structure of pramipexole dihydrochloride

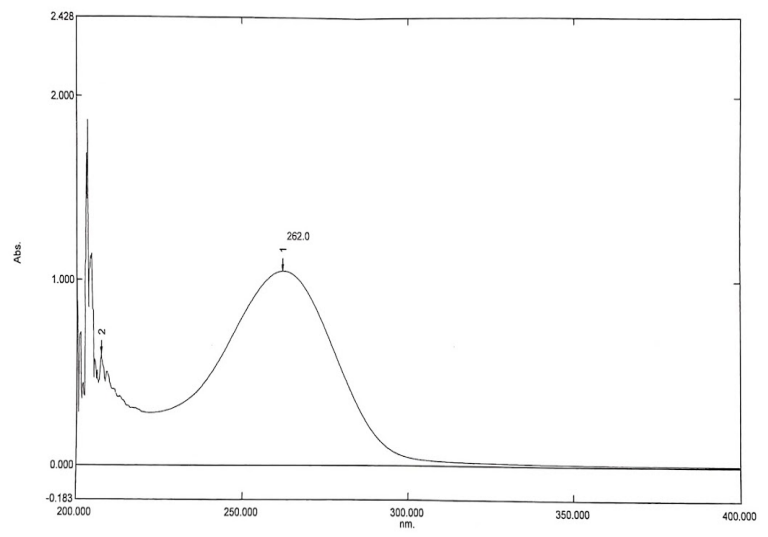

Fig. 2: UV absorbance spectra of pramipexole reference standard, maximum absorbance was observed at $262 \mathrm{~nm}$ 
These parameters were calculated using the formula $\mathrm{LOD}=3.3 \times \mathrm{SD} / \mathrm{S}$ and $\mathrm{LOQ}=10 \times \mathrm{SD} / \mathrm{S}$, where $\mathrm{SD}$ is the Standard Deviation of response (peak area) and $\mathrm{S}$ is the Slope of the calibration curve. LOD and LOQ were shown in the Table 1.

To determine the accuracy of the method, recovery study was performed. Known amount of pramipexole was added to a pre quantified sample solution of pramipexole tablet and the amounts were estimated by measuring the peak area ratios and the straight-line equation of calibration curve. The recovery studies were carried out three times over the specified concentration range of pramipexole. Accuracy was evaluated at three different concentrations equivalent to $50 \%, 100 \%$ and $150 \%$ of the active ingredient by calculating the recovery of pramipexole with \% RSD. The recovery studies of the proposed RP-HPLC method was discussed in the Table 2.

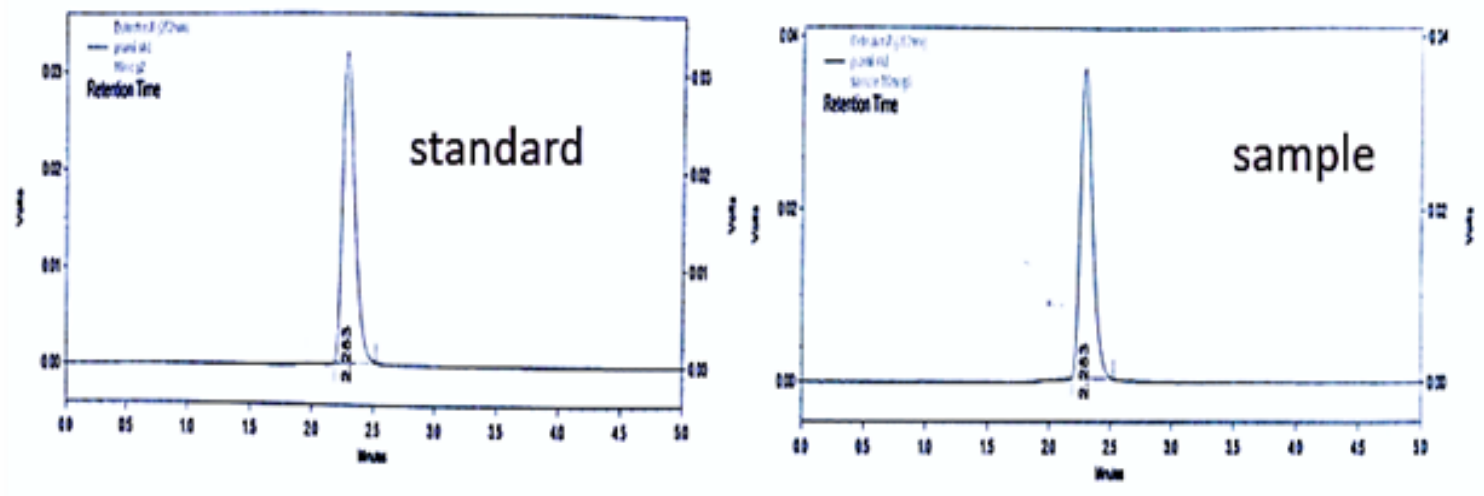

Fig. 3: Chromatogram of standard and sample $(10 \mu \mathrm{g} / \mathrm{ml})$, system suitability parameters such as column efficiency, theoretical plate and tailing factor were recorded from the standard chromatogram and amount is calculated from the peak area of sample chromatogram

TABLE 1: SYSTEM SUITABILITY PARAMETERS AND CALIBRATION CURVE DATA FOR PRAMIPEXOLE DIHYDROCHLORIDE (REFERENCE STANDARD)

\begin{tabular}{lc}
\hline Parameters & Values \\
\hline Theoretical plates & 2896 \\
Retention time & $2.28 \mathrm{~min}$ \\
USP tailing & 1.25 \\
Concentration range & $5-30 \mu \mathrm{g} / \mathrm{ml}$ \\
Slope & 23182 \\
Regression coefficient $\left(\mathrm{r}^{2}\right)$ & 0.999 \\
Standard error of intercept & 5551 \\
Number of points & 6 \\
\% RSD & 1.04 \\
LOD & $1.79 \mu \mathrm{g} / \mathrm{ml}$ \\
LOQ & $4.32 \mu \mathrm{g} / \mathrm{ml}$ \\
\hline
\end{tabular}

Note: Column efficiency, tailing factor and theoretical plates are within their acceptance limit, correlation coefficient $\mathrm{R}^{2}=0.999$ and $y=23182 x+3673$ showing the linearity of the calibration curve

TABLE 2: RECOVERY STUDIES AND PRECISION OF THE PROPOSED RP-HPLC METHOD

\begin{tabular}{lccccc}
\hline $\begin{array}{l}\text { Percentage (\%) } \\
\text { concentration }\end{array}$ & Area & $\begin{array}{c}\text { Amount added } \\
(\mu \mathrm{g} / \mathrm{ml})\end{array}$ & $\begin{array}{c}\text { Amount } \\
\text { recovered }(\mu \mathrm{g} / \\
\mathrm{ml})\end{array}$ & $\begin{array}{c}\text { Percentage (\%) } \\
\text { recovery found }\end{array}$ & $\begin{array}{c}\text { Mean RSD } \\
\text { recovery }\end{array}$ \\
\hline 50 & 339907 & 15 & 14.89 & 99.33 & 0.20 \\
100 & 471513 & 20 & 20.19 & 100.99 & 0.039 \\
150 & 586666 & 25 & 24.89 & 99.59 & 0.23 \\
Precision & & Intra-day precision & & Inter-day precision \\
Standard deviation & 0.749 & & 0.261 \\
\% RSD & 0.75 & & 0.26 \\
\hline
\end{tabular}

Note: Using recovery studies, accuracy was evaluated at different concentration equivalent to $50 \%, 100 \%$ and $150 \%$. The $\%$ RSD value below $2.0 \%$, indicates that the method is precise 
TABLE 3: RESULTS OF ROBUSTNESS

www.ijpsonline.com

\begin{tabular}{lcccc}
\hline Robustness conditions & & Retention time & Plate count & USP tailing \\
\hline \multirow{3}{*}{ Flow rate } & $0.8 \mathrm{ml} / \mathrm{min}$ & 2.34 & 2936 & 1.29 \\
& $1 \mathrm{ml} / \mathrm{min}$ (actual) & 2.28 & 2896 & 1.25 \\
& $1.2 \mathrm{ml} / \mathrm{min}$ & 2.16 & 2765 & 1.31 \\
$\mathrm{pH}$ of the buffer & 3.9 & 2.28 & 2890 & 1.25 \\
& 4.0 (actual) & 2.28 & 2896 & 1.25 \\
\hline
\end{tabular}

Note: This shows no change in the tailing factor, retention time and theoretical plate count, hence proving the developed method is robust

To determine the method precision the assay of six individual test samples with respect to the test samples were determined and \% RSD is calculated. As per International Council on Harmonisation (ICH) guidelines for the precise method the \% RSD should be less than $2.0 \%$. The precision results are shown in Table 2.

To determine the robustness of the proposed method small changes were made in the flow rate and $\mathrm{pH}$ of the phosphate buffer used. After the changes the tailing factor, retention time and plate count were not changed significantly, proving the developed method is robust. The results were shown in the Table 3.

When compared with the previously reported methods, the developed RP-HPLC method has a shortened analysis time and is also found to be accurate, rapid, precise and selective. The developed method has been completely validated showing satisfactory results for all method-validated parameters tested.

Thus, the above procedure can be conveniently used for the validation and assay determination of pramipexole dihydrochloride in pharmaceutical dosage form.

\section{Acknowledgements:}

The author proclaims their sincere gratitude to the management of Sri Ramachandra Institute of Higher Education and Research, Chennai for providing necessary background to carry out the research work.

\section{Conflict of interests:}

The authors declared no conflict of interest.

\section{REFERENCES}

1. Constantinescu R. Update on the use of pramipexole in the treatment of Parkinson's disease. Neuropsychiatr Dis Treat 2008;4(2):337.

2. Babu GS, Ch AI. Spectrophotometric determination of pramiexole dihydrochloride monohydrate. Asian J Chem 2007;19(1):816-8.

3. Gurupadayya BM, Vishwajith V, Srujana N. Spectrophotometric methods for the estimation of pramipexole dihydrochloride in pharmaceutical formulations. World J Chem 2009;4(2):15760.

4. Patil MH, Rokade MD. Determination of assay evaluation of pramipexole in Parkinson's disease by RP-HPLC method. Biol Forum 2013;5(1):78-83.

5. Ramababu C. Stability indicating RP-HPLC assay method for pramipexole dihydrochloride in pure and formulations. World J Pharm Sci 2015:2392-7.

6. Rajesh NV, Deepa Ramani D. RP-HPLC method for the determination pramipexole dihydrochloride in tablet dosage form. Int J Pharm Clin Res 2013;5(1):17-22.

7. Lavudu P, Rani AP, Sekaran CB, Kumar KS, Ramesh A. Determination of pramipexole dihydrochloride in tablet dosage forms by visible spectrophotometric method using acetyl acetone-formaldehyde reagent. Chem Sci J 2012.

8. Dey S, Pradhan PK, Upadhayay UM, Desai K, Niranjani D. Method development and validation of pramipexole by UV spectrophotometric method. J Pharm Res 2012; 5(11):5052-54.

9. Guo W, Li G, Yang Y, Yang C, Si L, Huang J. LC-MS/ MS analysis of pramipexole in mouse plasma and tissues: Elimination of lipid matrix effects using weak cation exchange mode based solid-phase extraction. J Chromatogr B 2015;988:157-65.

10. Jeffery GH, Basset J, Mendham J, Denny RC, Vogel's textbook of quantitative chemical analysis, $5^{\text {th }}$ ed. Longman Group UK Limited: John Wiley \& Sons, Inc.; 1989.

11. ICH Steering Committee. ICH harmonized tripartite guideline, Validation of analytical procedures, text and methodology Q2(R1). In Proceedings of the International Conference on Harmonization of Technical requirements for Registration of Pharmaceuticals for Human Use, London, UK; 1996.

12. VICH Steering Committee. Validation of analytical procedures: Definition and terminology. ICH, Geneva: Switzerland; 1998. 